\title{
The effect of family supportive supervisor behaviors and work-family culture on turnover inten- tion and work-family conflict
}

\author{
Ximena Campos-Garcia ${ }^{a^{*}}$, Ruben Guevara ${ }^{\mathrm{b}}$ and Sandra Idrovo-Carlier
}

${ }^{a}$ CENTRUM Catolica Graduate Business School, Lima, Peru - Pontificia Universidad Catolica del Perú, Lima, Perú y Escuela Internacional de Ciencias Económicas y Administrativas, Universidad de La Sabana, Chía, Colombia

${ }^{b}$ CENTRUM Catolica Graduate Business School, Lima, Peru - Pontificia Universidad Catolica del Perú, Lima, Perú

${ }^{c}$ Departamento de Dirección de Personas en las Organizaciones, INALDE Business School, Chía, Colombia

\begin{tabular}{l}
\hline C H R O N I C L E \\
\hline Article history: \\
Received: April 4, 2021 \\
Received in revised format: \\
April 272021 \\
Accepted: May 18, 2021 \\
Available online: \\
May 18, 2021 \\
\hline Keywords: \\
Family supportive supervisor be- \\
haviors \\
Work-family culture \\
Work-family conflict \\
Turnover intention \\
Work-family interface \\
Public security organizations \\
Latin America
\end{tabular}
\begin{abstract}
A B S T R A C T
The purpose of this research was to look into the work-life interface of professionals in a demanding and high-risk occupation in an organization in the security sector. Specifically, it focuses on the interaction between supervisor behaviors and culture with turnover intention and work-family conflict. The present study centers on data from a public security organization (3861) in a Latin American country. The validity of the measuring instruments was evaluated through Confirmatory Factor Analysis (CFA). Structural Equation Modeling (SEM) was then applied to evaluate the relationship between variables. Results found show a statistically significant negative impact of the supervisor behaviors in organizational (turnover intention) and individual outcomes (work-family conflict). At the same time, organizational culture negatively affects turnover intentions and workfamily conflict. While confirming results coming from the private sector in other countries, the importance of supervisor behaviors and culture provides implications for work and family practices in this type of organization.
\end{abstract}

\section{Introduction}

Research on the work-life interface carried out in different countries has grown in the last years (Idrovo Carlier et al., 2012; Idrovo \& Bosch, 2019; Las Heras, Bosch et al., 2015; Pecino et al., 2018). Recently, there is more significant interference in balancing work obligations and family or personal responsibilities for most employees (Shabir et al., 2021). Le et al. (2020) stated that researchers in Asia have examined the work-life interface constructs on work and non-work outcomes, but academics are debating whether work-life constructs from the west must be investigated (Idrovo Carlier et al., 2012; Idrovo \& Bosch, 2019; Las Heras et al., 2015; and Las Heras et al., 2015). Therefore, these studies point to the need to investigate how work and life outside work interface and interact in Latin America (Shockley et al., 2017). As of 2016, according to Shockley et al. (2017), only seven percent of published research considered Latin American contexts. However, research from those countries, has focused on the work-life interface mostly in firms and organizations from the private sector. Specific and demanding professions that impose additional pressures to the work-life interface, such as police officers (Alhashmi et al., 2017; Amendola et al., 2021), fire-fighters (Wu et al., 2019), healthcare workers (Blanco-Donoso et al., 2021; Deng et al., 2021), military personnel (Carvalho \& Chambel, 2017), among others working in public service organizations have been overlooked (Carvalho \& Chambel, 2017; French et al., 2018; Yanos et al., 2020). The nature of the work in a demanding profession can directly affect the work-life interface; work-related energy and both psychological and behavioral pressures evoke family

* Corresponding author.

E-mail address: ximena.campos@unisabana.edu.co (X. Campos Garcia) 
tensions (Lachowska et al., 2018; Wadsworth \& Southwell, 2011; Yanos et al., 2020). Similarly, aspects of workload (i.e., working hours, days in training and perceived work overload), hours of sleep, health and morale are considered the strongest predictors of work-family conflict (WFC) among demanding and high-risk professionals such as police officers, fire-fighters, paramedics, military personnel, doctors and nurses (Liao et al., 2019; Pien et al., 2021). At the same time, difficulty in achieving work-life balance due to the particular demands of certain jobs and to the high risks to health in these professions are two reasons affecting well-being (Brooks \& Greenberg, 2018) and turnover intention (Blanco-Donoso et al., 2021; Dupré \& Day, 2007; Frone \& Blais, 2019; Van der Heijden et al., 2018) of the professionals involved in these occupations. This, in turn, represents a higher-than-average cost for the organizations that employ these workers due to the specialized training they undergo and the costly processes of talent attraction, selection and retention involved (Hughes et al., 2020). Furthermore, as mentioned by Adams et al. (2006), the organizational settings of these professions are characterized by a strict hierarchy that reinforces the role of the supervisor and creates a culture that may hinder or help in developing work-family supportive practices.

Within this setting, it seems important to look at how family supportive supervisor behaviors and work-family organizational culture affect outcomes such as turnover intention and work-family conflict in employees in a demanding profession. This paper contributes to the literature on the work-life interface in two ways. First, by increasing the understanding of how supervisors' supportive behaviors and organizational culture relate to two specific outcomes: one at the individual level - workfamily conflict - and one at the organizational level - turnover intention - in a hierarchical organization and demanding profession such as that in security forces. The second contribution is to the literature by expanding research results and knowledge related to Latin America, a geographical area where they are scarce (Shockley et al., 2017).

\section{Literature review and hypotheses}

The search for balance or integration between work and family and personal life continues to be important to organizations because it affects their human factor by placing increasing demands on them and their people (Fleetwood, 2007; J. Greenhaus et al., 2006; Halinski \& Duxbury, 2019; Idrovo \& Bosch, 2019; Thörnqvist, 2006). Due to work-life interface issues, companies face competition in attracting and retaining talent, high levels of absenteeism, increased turnover intention, lack of commitment, burnout and health and well-being issues in general (Blanco-Donoso et al., 2021; Deng et al., 2021; Sánchez-Vidal et al., 2012; Van der Heijden et al., 2018; Van Steenbergen \& Ellemers, 2009; Yanos et al., 2020). The current growth in work-life interface research reflects a period of social and economic development, during which there has been profound variations in the nature of work, as well as an increase in the consideration for the well-being of employees (Carvalho \& Chambel, 2016; Odle-Dusseau et al., 2016). The increase of women entering the labor force, long working hours, the difficult commutes from/to work, variations in ways of hiring, among other issues have sparked academic interest in how different organizations deal with these new circumstances (Allen, 2012; Halinski \& Duxbury, 2019; Hirschi et al., 2019; Kelly et al., 2008; Lefrancois et al., 2017; Mishra \& Bhatnagar, 2019). Li et al. (2019) found that some operational and administrative factors influenced work stress and work engagement among police officers. Similarly, Minamizono et al. (2019) confirmed other studies, concluding that nurses who experience burnout were more likely to intend to leave work. Congruently, research has grown on the consequences of work and family interferences on employees' well-being (Pecino et al., 2018).

Yet this growing body of literature has not considered certain demanding and high-risk professions, such as police officers, fire-fighters, paramedics, military personnel, doctors and nurses who work within the hierarchical structures that are characteristic of their jobs (Russell, 2014). There is growing academic interest in some social trends such as the changing nature of work and work-life issues (Powell et al., 2019). Adding to the challenge of managing the work-life interface, the way these professionals juggle work and life outside work beyond the difficulty of their jobs impacts directly on their intention to remain in their organizations as well as on their well-being and performance. Interestingly enough, as Larsson et al. (2016) suggested in their systematic review of research about police, firefighters, military personnel and paramedics, "daily hassles in most cases were stronger associated with outcomes such as psychological symptoms and burnout, than were the experiences of major, more or less traumatic events" (p. 365). They found that organizational problems correlate more closely with healthrelated outcome measures than with operational stressors, while non-work problems are negatively associated with work performance and psychological well-being (Blanco-Donoso et al., 2021; Halinski \& Duxbury, 2019; Lachowska et al., 2018; Sonnentag \& Fritz, 2015; Van der Heijden et al., 2018). Even in these demanding and high-risk professions, the daily organizational routines and practices are a stronger source of interference with the non-work domain, work performance and employee well-being.

\subsection{Organizational and professional context}

Security personnel are expected to be willing to sacrifice their lives, should the need arise, in order to fulfill the organization's mission. In addition to the risk of injury or death, the demands of the profession also involve frequent relocation, which may be in a foreign country, and periodic separation from one's family (Burrell et al., 2006; Campaniço Cavaleiro et al., 2019; Liao et al., 2019). Leaving these aside, there are other job characteristics that male and female security employees share with high demanding professions such as firefighters, police personnel, doctors and nurses. These include stressful conditions, a 
high number of working hours, 24/7 availability (shift work) and pressures of the job related to the responsibilities and complexity of the work. These demands affect their job performance, family satisfaction and overall well-being (Brooks et al., 2018).

\subsection{Hierarchical Organizations}

A hierarchy culture contains some organizational characteristics, such as large numbers of standardized procedures, multiple hierarchical levels and the importance of rules - even in small organizations (Cameron \& Quinn, 2006). Large organizations and government or public agencies are usually dominated by a hierarchical culture, according to Rasmussen (2020). This kind of public organization has the objective of offering well-being, security, and productivity to the population. A hierarchical organization has characteristics of controlling orientations; timeliness; consistency and uniformity, and having a leader who is a coordinator, monitor and organizer. It is driven by the values of efficiency, reflecting the theory of control, efficiency and effectiveness (Cameron \& Quinn, 2006). These characteristics describe the way professions are organized. Until the 1960s, almost every book on management and organizational studies assumed that Max Weber's hierarchy or bureaucracy was the ideal form of organization because it led to stable, efficient, highly consistent products and services (Cameron \& Quinn, 2006; Fantuzzo, 2015).

\subsection{Demanding professions}

Since the early 1960s, work stress as a life-structuring concept has been an important societal issue that increased scientific attention on industrial and organizational, psychosocial and occupational health sciences (Väänänen et al., 2012). Väänänen el al. (2012) found that in the 1980s it was concluded that role characteristics, including role ambiguity, role conflict, role overload, role underload and role status congruency, have been associated with stress. Karasek (1979) suggested two important elements of the work environment at the individual level: (1) the job demands placed on the worker and (2) the worker's decision on how to meet these demands. Although stressors such as fear of unemployment or occupational career problems might contribute to job pressures, some authors found that, when a wide variety of sources are reviewed, the demands related to accomplishing the task are the most usually cited source of job pressure (Karasek, 1979).

A process of depletion from a high level of job demands (such as high workload) can produce burnout and other associated health problems. Some of the characteristics of a demanding profession are high working time demands, low working time control, heavy workload, work pressure, emotional and demanding interaction and task ambiguity (Demerouti et al., 2001; Lingard et al., 2012; Montgomery et al., 2006; Pien et al., 2021; Powell et al., 2019; Van Steenbergen et al., 2018). These cause stress for employees and deplete employees' mental and physical energy resources (Van Steenbergen et al., 2018). Source of pressure at work may change for each person and evoke different reactions from different people in demanding professions such as the armed forces, police officers, firefighters, doctors, nurses, directors' seniors, corporate and teachers. Both women and men are exposed to a wide range of stressor actions as a part of their training and work assignments. Additionally, in a military or medical context, women may also experience stressors associated with being a woman in a traditionally and principally male work environment (Bray et al., 2010). Similar situations may affect men entering the nursing profession. The job demands and stresses have remained the same or increased, even when the size of the workforce in those occupations has varied (Bray et al., 2010; Li et al., 2019).

Occupations that have characteristics of demanding professions are organized into hierarchical systems. For example, with respect to armed forces, Sharma (2015) found that the lack of control at work is the most severe and influential stressor in the Indian army, followed by role conflict and workload. This study also showed that the most significant variable contributing to ineffective leadership style was an absence of freedom to talk about work and/or home issues, and Lingard et al. (2012) found that working time demands were positively correlated with time- and strain-based work-family interference. Li et al. (2019) and Amendola et al. (2021) found that work-family conflicts and organizational factors affected work stress among police officers. Powell et al. (2019) argued that many academics in the work-life field tend to divide the various domains that are important to people into two categories - the work domain and all other domains. The interaction between work and the rest of life is more complex, however, than a dichotomy between work and life outside work.

\subsection{Family supportive supervisor behaviors and turnover intention}

While organizations implement policies that may aid their employees in balancing their work-life routines in order to reduce negative organizational and individual outcomes (Bosch et al., 2018; Lapierre \& Allen, 2006; Las Heras, Spela, et al., 2015), the effectiveness of these policies remain questionable. The mere presence of policies does not guarantee the existence of practices. As Kelly et al. (2008) suggested, it is important to identify the mechanisms through which a policy becomes a practice that helps employees balance their life and work realms. The literature has recognized the role of supervisors as one such mechanism (Bosch et al., 2018; Rhoades \& Eisenberger, 2002). Supervisors and managers are the linchpins in most organizations, and they channel the support resources offered by employers. Employees identify the intent of the organization 
with the actions of the supervisor if supervisor behaviors are sanctioned or promoted by it (Mccarthy et al., 2010). It is the supervisor who distributes the organization's resources that alleviate or hinder employees' attempts to balance work and life outside work and in doing so, they become a resource themselves that can mitigate or not the negative consequences of such attempts. Some strategies used by the supervisor may modify how, when, or where work gets done without affecting general performance or avoiding negative career consequences (Behson, 2002). These strategies acquire more power when exercised within a hierarchical organization where chains of command are strict and must be followed in order to achieve the goals of the organization (Wadsworth \& Southwell, 2011).

Hammer et al. (2009) developed a more refined measure that better captures the nuances of the relationship between supervisors' behaviors and employees' family and personal needs: family supportive supervisor behaviors (FSSB). They defined FSSB as a multidimensional construct that "consist of behaviors displayed by managers that aim to provide emotional and instrumental support, role modelling, and creative management of work-life issues in order to facilitate employee effectiveness" (Hammer et al., 2009, p. 1). On the other hand, employees that see their job expectations or work relationships falter start thinking about leaving the organization in the near future. Turnover intention is defined as the intention of leaving an organization, should the possibility arise, or thinking constantly about it (O'Reilly et al., 1991). Employees in this situation decrease their effectiveness because they become less focused, more distant from their work and work environment, more likely to neglect their duties, therefore affecting organizational results (Flint et al., 2013; Keaveney \& Nelson, 1993). Moreover, turnover intention is the best predictor of actual turnover (Armitage \& Conner, 2001; Huffman, Adler, Dolan, \& Castro, 2005; Idrovo \& Bosch, 2019; Las Heras, Spela, et al., 2015), and organizational turnover has an increasing cost in an employee's annual salary (Allen, 2001). This cost includes and varies according to the requirements for high-skill training and rates of talent attraction and selection (Caillier, 2016; Hatch \& Dyer, 2004; Holtom et al., 2008; Shaw et al., 2005). As Holtom et al. (2008) point out, there is no line in the financial statements that captures the cost of turnover, "Instead, the costs are buried in line items like recruitment, selection, temporary staffing and training. Or worse still, the real but unmeasured costs from losses of customer service continuity or critical implicit knowledge are never calculated." (p. 236). Similarly, the turnover cost for those organizations that employ high risk and demanding professionals is a growing problem, whether they are soldiers (Dupré \& Day, 2007); police officers, fire-fighters (Burakova et al., 2014) or nurses (Duxbury \& Halinski, 2018). And there is a further problem in that, due to the specific training requirements that these occupations demand, this may result in higher-than-average costs of turnover (Dupré \& Day, 2007).

Within this scenario, these organizations try to identify how to better face this challenge through implementation and practices that lower turnover intentions (TI). As noted earlier, organizational support through the behaviors and actions of supervisors have been found to be one way of achieving that, especially when the cause of that TI is related to work-life balance. The employees who perceive higher levels of family supportive supervisor behaviors (FSSB) will in turn have greater job satisfaction and lower levels of turnover intentions (Hammer et al., 2009; Kossek et al., 2018; Las Heras, Spela, et al., 2015; Mittal \& Bienstock, 2019; Odle-Dusseau et al., 2016). The same seems to happen to those professionals in high-risk and demanding occupations. Their supervisors' behaviors have a stronger impact in their work and non-work lives due to the special features that their jobs entail (Dick \& Hyde, 2006; Dupré \& Day, 2007; Hammer et al., 2019; Matthews et al., 2014; Mills et al., 2014; Wadsworth \& Southwell, 2011). Thus, we hypothesize that:

\section{$\mathbf{H}_{1}$ : Family supportive supervisor behaviors are related negatively to turnover intention in public security organizations.}

\subsection{Work-family culture and turnover intention}

If we widen the view to look at organizational culture, we see that different variables come into play: language, symbols, behaviors, rules and feelings. According to Cameron and Quinn (2006), an organization's culture is reflected in what is valued, the main leadership styles, the language and symbols, the procedures and practices, and the definitions of success that make an organization unique. Work-family culture is friendly to the family needs of its employees, is defined by the communal assumptions, beliefs, and values regarding the extent to which it actually supports and values the integration of their employees work and family lives (C. A. Thompson et al., 1999). Thompson et al. (1999) found that more supportive cultures were associated with greater use of company benefits; employees felt safe using family-friendly programs because they perceived that it was acceptable to do so. According to Brough and Driscoll (2010), work-life interface research runs the risk of following in the footsteps of occupational stress research, thus losing sight of the specific outcomes of work-life interface at individual, organizational, and national levels. They also suggest that at the organizational level, some types of work-family culture could be more favorable than others for reducing certain unwanted organizational outcomes, one of which is turnover intention. Thompson et al. (1999) found that the presence of a work-family culture that helps integrate work and life outside work was related negatively to work-family conflict and turnover intention. Haar and Roche (2010) also found that family-supportive organizational environments were associated negatively with turnover intention and positively, with job and life satisfaction. Similarly, Thompson and Prottas (2005) showed that supportiveness of an organization's work-family culture was negatively related to stress, turnover intention, and both forms of work-family conflict. Allen and Martin (2017) suggested continuing to produce research findings with the potential to improve the well-being of individuals, families, organizations and economies. 
The actual "around-the-clock" work culture, in which workers are expected to be available all the time (Miller, 2015) together with the specific demands of professionals such as paramedics, police officers, armed forces personnel, fire-fighters, etc. present challenges for the integration of work and personal lives. Potential resistance among the individuals in the organization appears when the work-family culture is not supportive of family-friendly policies or facilitates that balance the work-life interface to the extent possible (Rofcanin et al., 2017). In the case of the organizations where these demanding professions develop, such resistance leads to the desire to leave the organization, with the consequences already discussed. An organizational culture that hinders integration of work and life outside work has been found to relate to turnover intention in firefighters (Burakova et al., 2014), military personnel (Dupré \& Day, 2007), and federal agencies (Caillier, 2016). Thus, we hypothesize that:

\section{H2: Work-family culture is related negatively to turnover intention in public security organizations.}

\subsection{Family supportive supervisor behaviors and work-family conflict}

Within the literature on work-family, work-family conflict is one of the constructs that has been studied the most (Allen \& Martin, 2017; Greenhaus \& Beutell, 1985; Liao et al., 2019). J. H. Greenhaus and Beutell (1985) defined work-family conflict as "a form of inter-role conflict in which the role pressures from the work and family domains are mutually incompatible in some respect" (p. 77). Conflict is generated when work and family share the same resources and one person must play both roles, and that meeting the demands of one role makes it difficult to meet the demands of the other role (J. H. Greenhaus, 2016). The interference has been operationalized in two ways: work interfering with family and family interfering with work.

Work-family conflict has been associated with burnout, poor well-being at work and, in general, with negative outcomes (Carvalho \& Chambel, 2016; Frye \& Breaugh, 2004; Griffin \& Sun, 2018; Liao et al., 2019; Rantanen et al., 2013). Work characteristics are important factors that explain work-family conflict, particularly workload and high level of demands (Byron, 2005). Work-family conflict can act as a chronic job demand and may deplete employees' mental and physical resources, which may lead to burnout and health deterioration (Schaufeli \& Bakker, 2004).

The supervisor's role becomes of utmost importance for reducing work-family conflict (WFC) in organizations (Hammer et al., 2011; Han \& McLean, 2020). Even more so for professionals in high-risk and occupations that are demanding with respect to WFC. These professionals are employed by organizations (law enforcement agencies, fire-fighting organizations, armed forces institutions, among others) with very centralized and hierarchical structures in which the supervisor manages the roll call and the strict orders that personnel are supposed to follow. Instructions are orders to be followed, but notwithstanding this, there is room for the supervisors to behave in a way that employees' well-being and work-life balance is encouraged rather than diminished (Chambel et al., 2015, pp. 299-300). As we mentioned earlier, supervisors become the linchpin between the quality of life and flexibility of the individuals, since access to most types of leave or flexibility programs must have approval by the supervisor, and they also decide whether and when a job is or is not complete (Wadsworth \& Southwell, 2011). In the case of the military, for example, using a sample of 175 employees of the Portuguese Marine Corps, Carvalho and Chambel (2017) found a significant and negative relationship between family supportive supervisor behaviors and workfamily conflict. Equal results were obtained by Campaniço Cavaleiro et al. (2019) for members of the Portuguese Navy. Similarly, Similarly, the supervisor's roleis a key for reducing work-family conflict and improving work-life balance for firefighters (Wu et al., 2019), nurses (Chen et al., 2017), and police officers (Duxbury \& Halinski, 2018). Thus, we hypothesize that:

\section{H3: Family supportive supervisor behaviors are related negatively to work-family conflict in public security organizations.}

\subsection{Work-family culture and work-family conflict}

Family supportive supervisor behaviors are not the only resource that employees have at their disposal, however. These behaviors take place within an organizational set of norms, beliefs and values that make possible and/or facilitate a workfamily culture that supports and cares for the balance between their employees' work and life outside work. For example, Thompson and Prottas (2005) showed in their research that supportiveness of an organization's work-family culture was related negatively to stress, intentions to quit the job, and both forms of work-family conflict. Using meta-analysis of 85 studies, Kossek et al. (2011) found that the presence of an organizational culture where there was specific support for workfamily integration had a negative relationship to work-family conflict that was stronger than the relationship between general organizational support and work-family conflict. Similarly, in a meta-analysis based on 1021 effect sizes and 46 countries, French et al. (2018) dissected the relationship between social support and work-family conflict, and found that organizational support may be the most important overall source of support when trying to mitigate work-family conflict.

Consistent with these results, using a sample of 227 Turkish white-collar managers and professionals, Bayazit and Bayazit (2017) found that perceptions of work-family culture norms were the most robust predictor of work-family conflict in both 
directions. These findings corroborate those obtained by Lapierre et al. (2008) in Anglo-Saxon countries. They found a causal process whereby employees working in an environment viewed as more family supportive experience lower levels of workfamily conflict.

O'Neill and Rothbard (2015) concluded, when studying the characteristics of the masculine organizational culture of firefighters in the United States, that in this male-dominated, demanding profession one negative outcome of their daily work was work-family conflict. Further to this, they found out that joviality as a predominant work-family culture characteristic accentuates the positive impact of work-family conflict on individual health. We therefore hypothesize that:

H4: Work-family culture is related negatively to work-family conflict in public security organizations.

Fig. 1 shows the research hypotheses used in this study.

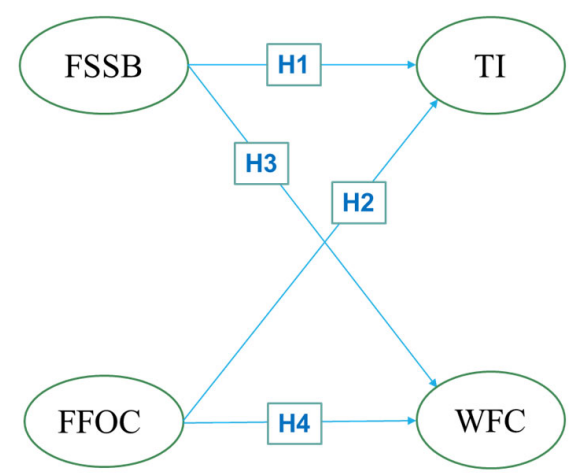

Fig. 1. Theoretical model and hypotheses about the impact of family supportive supervisor behaviors and work-family culture on turnover intention and work-family conflict of a demanding profession in a hierarchical organization

\section{Methods}

\subsection{Sample and procedures}

To test the hypotheses, data were collected from professionals in a demanding and high-risk occupation and belonging to an organization in an organization in security sector in Latin American country. Members of the organization were located in five different cities. The definition of the final sample size was that city 1 had 3,000 observations; city 2 had164; city 3, 279; city 4, 384 and city 5 had 173 observations. After checking for duplicity and validity, the final sample was reduced to 3,861 responses. The average age is 35.7 years, and $89 \%$ of respondents were men, while $11 \%$ of the sample were women. The average number of children in the sample is 1.6, while the national average number of children for Latin American country is 2.35. The sample size is representative according to the characteristics of the sample: standard deviation of 0.54 , confidence level of $99.99 \%$ and error of 0.026 . Data was collected using four previously validated research instruments developed to measure FSSB (Hammer et al., 2009), FFOC (Thompson, Beauvais, \& Lyness, 1999), TI (O'Reilly, Chatman, \& Caldwell, 1991), and WFC (Matthews, Kath, \& Barnes-Farrell, 2010). The FFSB (family supportive supervisor behaviors) scale was developed by Hammer et al. (2009). It uses a 7-point Likert scale: $1=$ very dissatisfied, $7=$ very satisfied). The coefficient alpha for this measure in the sample was 0.97 (Cronbach Ordinal). The FFOC (work-family culture) measurement was created by Thompson et al. (1999). It uses a 7-point Likert scale. The coefficient alpha for this measure was 0.84 (Cronbach Ordinal). The TI (turnover intention) scale used by O'Reilly et al. (1991) uses a 7-point Likert scale. The coefficient alpha for this measure was 0.88 (Cronbach Ordinal). Finally, the WFC (work-family conflict) scale used by Matthews et al. (2010) uses a 7-point Likert scale. The coefficient alpha for this measure was 0.765 (Cronbach Ordinal). Control variables used were, children (no $=0$, yes $=1$, and if "yes" the total) and gender ( male $=0$, female $=1)$.

\subsection{Data analysis}

This study used SAS 9.4 software to check the adaptability and appropriateness of the proposed model and the hypotheses introduced. SAS is a modular, integrated and hardware-independent system of statistical software. It is a particularly powerful tool for social scientists (O'Rourke \& Hatcher, 2013). Firstly, the data was analyzed for normality and heteroscedasticity, showing a normality characteristic. The validity of the measuring instruments FSSB, FFOC, IT and WFC was evaluated through Confirmatory Factor Analysis (CFA). Structural Equation Modelling (SEM) was then applied to evaluate the relationship between IT and WFC and the independent variables: FSSB and FFOC. Additionally, the invariance of the model was evaluated for gender and employees with or without children. Cronbach's internal reliability statistics for each scale, and multivariate normality (skewness and kurtosis) were evaluated for the data collected with the mentioned research instruments. 


\section{Results}

Results show a significant negative impact of family supportive supervisor behaviors in the organizational (turnover intention) and individual (work-family conflict) outcomes. At the same time, work-family culture negatively affects turnover intentions and work-family conflict. Table 1 shows the results of confirmatory factor analysis (CFA) to the test of goodness of fit of the model.

Table 1

Results of confirmatory factor analysis

\begin{tabular}{|c|c|c|c|}
\hline Variable & & $\mathrm{CA}$ & Factor Load \\
\hline \multirow{3}{*}{ Work-family culture } & WFCON1 & \multirow{3}{*}{0.84} & 0.533 \\
\hline & WFCON2 & & 0.693 \\
\hline & WFCON3 & & 0.649 \\
\hline \multirow{6}{*}{ Family supportive supervisor behaviors } & SUAP1 & \multirow{6}{*}{0.97} & 0.736 \\
\hline & SUAP2 & & 0.805 \\
\hline & SUAP3 & & 0.799 \\
\hline & SUAP4 & & 0.815 \\
\hline & SUGE1 & & 0.796 \\
\hline & SUSI1 & & 0.809 \\
\hline \multirow{3}{*}{ turnover intention } & INTID & \multirow{3}{*}{0.88} & 0.689 \\
\hline & INTTR & & 0.724 \\
\hline & INTFR & & 0.738 \\
\hline \multirow{3}{*}{ Work-family culture } & CUREC I & \multirow{3}{*}{0.77} & 0.421 \\
\hline & CUFLE_I & & 0.618 \\
\hline & CUPRS_I & & 0.479 \\
\hline
\end{tabular}

Note: CA = Cronbach's Alpha

For CFA, the model adjustments were evaluated through the comparative fit index (CFI), the standardized root mean square residual (SRMR) and the root mean square error of approximation (RMSEA), and its confidence interval calculated at $90 \%$. To modify the measurement model, Lagrange multipliers were used for release parameters, and the Wald test for restriction of parameters was applied. Each modification was applied sequentially, one parameter at the time, based on a significant effect $(p<0.05)$, change of the values of $\chi 2$, and improvement in the indexes mentioned above: RMSEA and standardized RMR $($ SRMR $)<0.055$, CFI $>0.94$, and the upper limit of the $90 \%$ confidence interval for the root mean square error of approximation (RMSEA) <0.09 (Hu \& Bentler, 1999; O’Rourke \& Hatcher, 2013).

\section{Reliability and validity}

Reliability and validity of the constructs were evaluated in the final model: reliability $>0.39$, composite reliability $>0.7$ and variance extracted $>0.49$ units (Fornell \& Larcker, 1981; O’Rourke \& Hatcher, 2013). Convergence validity was assessed by $t$-tests on parameters and discriminant validity on the $95 \%$ confidence interval for covariances. The estimates were made using the Maximum Likelihood (ML) method over the Pearson product-moment correlation matrix. Results show a significant negative impact of family supportive supervisor behaviors in the organizational (turnover intention) and individual (workfamily conflict) outcomes. At the same time, work-family culture negatively affects turnover intentions and work-family conflict. The negative relationship expected between family supportive supervisor behaviors and turnover intention $\left(\mathbf{H}_{\mathbf{1}}\right)$ is confirmed by the regression (Table 2); FSSB has a significant negative effect on TI $(\beta=-0.24, \mathrm{SE}=0.018, \mathrm{p}<0.001)$. Similarly, the negative relationship expected between work-family culture and turnover intention $\left(\mathbf{H}_{2}\right)$ is supported by the results (Table 2); FFOC has a significant negative effect on TI $(\beta=-0.28, \mathrm{SE}=0.031, \mathrm{p}<0.001)$.

Table 2

Turnover Intention

\begin{tabular}{|c|c|c|c|c|c|}
\hline Variable & Predictor & Estimator & Standard Error & $\mathrm{T}$ value & $\operatorname{Pr}>|t|$ \\
\hline INTID & $\mathrm{F} 1$ & 0.79720 & 0.02216 & 35.9669 & $<.0001$ \\
\hline INTTR & $\mathrm{F} 1$ & 1.00000 & & & $<.0001$ \\
\hline INTFR & $\mathrm{F} 1$ & 0.85180 & 0.02172 & 39.2161 & $<.0001$ \\
\hline CUREC_I & $\mathrm{F} 2$ & 0.76050 & 0.04586 & 16.5831 & $<.0001$ \\
\hline CUFLE_I & $\mathrm{F} 2$ & 0.91965 & 0.05593 & 16.4431 & $<.0001$ \\
\hline CUPRS_I & $\mathrm{F} 2$ & 1.00000 & & & $<.0001$ \\
\hline SUAP1 & F3 & 0.84905 & 0.01263 & 67.2014 & $<.0001$ \\
\hline SUAP2 & F3 & 0.95749 & 0.01315 & 72.8307 & $<.0001$ \\
\hline SUAP3 & F3 & 1.00000 & & & $<.0001$ \\
\hline SUAP4 & F3 & 0.99612 & 0.01290 & 77.2435 & $<.0001$ \\
\hline SUGE1 & F3 & 0.90103 & 0.01337 & 67.4080 & $<.0001$ \\
\hline SUSI1 & F3 & 0.94906 & 0.01309 & 72.4961 & $<.0001$ \\
\hline F1 & $\mathrm{F} 2$ & -0.27807 & 0.03150 & -8.8278 & $<.0001$ \\
\hline F1 & F3 & -0.23723 & 0.01786 & -13.2857 & $<.0001$ \\
\hline
\end{tabular}

*indicates significances at the $p<0.001$ level. 
The negative relationship expected between family supportive supervisor behaviors and work-family conflict (H3) is confirmed by the regression (Table 3 ); FSSB has a significant negative effect on WFC $(\beta=-0.20, \mathrm{SE}=0.017, \mathrm{p}<0.001)$. The negative relationship between work-family culture and work-family conflict (H4) is confirmed by the regression (Table 3 ); FFOC has a significant negative effect on $\operatorname{WFC}(\beta=-0.46, \mathrm{SE}=0.031, \mathrm{p}<0.001)$.

Table 3

Work-family conflict

\begin{tabular}{|c|c|c|c|c|c|}
\hline Variable & Predictor & Estimator & $\begin{array}{l}\text { Standard } \\
\text { Error }\end{array}$ & T Value & $\operatorname{Pr}>|t|$ \\
\hline WFCON1 & F1 & 0.56914 & 0.02567 & 22.1688 & $<.0001$ \\
\hline WFCON2 & F1 & 1.00000 & & & $<.0001$ \\
\hline WFCON3 & $\mathrm{F} 1$ & 0.90246 & 0.03444 & 26.2068 & $<.0001$ \\
\hline CUREC_I & $\mathrm{F} 2$ & 0.72101 & 0.04099 & 17.5887 & $<.0001$ \\
\hline CUFLE_I & F2 & 0.80367 & 0.04337 & 18.5300 & $<.0001$ \\
\hline CUPRS_I & $\mathrm{F} 2$ & 1.00000 & & & $<.0001$ \\
\hline SUAP1 & F3 & 0.85029 & 0.01247 & 68.1727 & $<.0001$ \\
\hline SUAP2 & F3 & 0.95844 & 0.01298 & 73.8179 & $<.0001$ \\
\hline SUAP3 & F3 & 1.00000 & & & $<.0001$ \\
\hline SUAP4 & F3 & 0.99275 & 0.01271 & 78.1369 & $<.0001$ \\
\hline SUGE1 & F3 & 0.89852 & 0.01317 & 68.2131 & $<.0001$ \\
\hline SUSI1 & F3 & 0.94615 & 0.01293 & 73.1631 & $<.0001$ \\
\hline F1 & $\mathrm{F} 2$ & -0.46316 & 0.03167 & -14.6241 & $<.0001$ \\
\hline F1 & F3 & -0.19993 & 0.01712 & -11.6749 & $<.0001$ \\
\hline
\end{tabular}

*indicates significances at the $p<0.001$ level.

All the four hypotheses as well as the proposed model were confirmed. When controlling for sex and if participants have children or not, the model behaves in the same way.

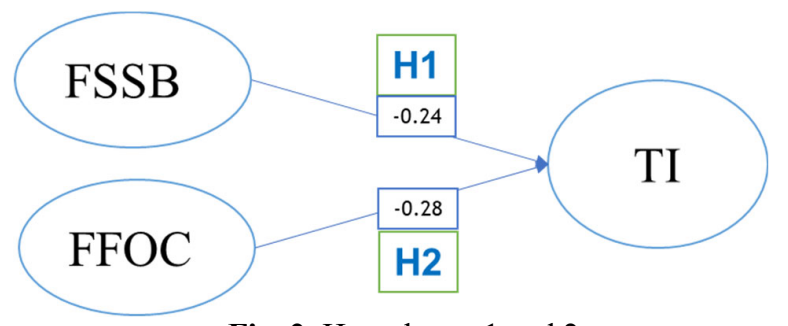

Fig. 2. Hypotheses 1 and 2

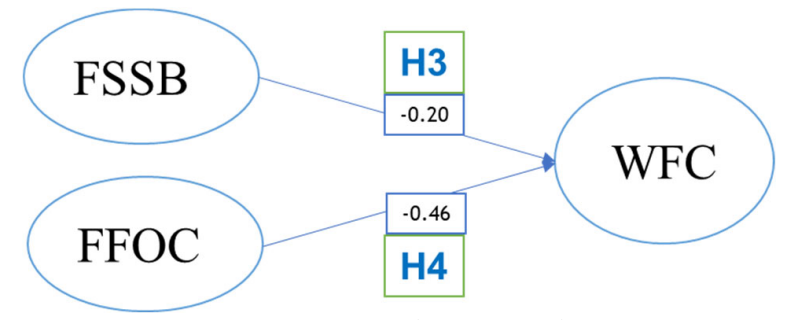

Fig. 3. Hypotheses 3 and 4

The following indicators support the accuracy of the model, with the chi-Square test showing a result of 631.7 and 51 degrees of freedom. The comparative fit index obtains a result of 0.98 with a root mean square error of approximation of 0.0576 and a CI of a 90\% [0.054-0.062] for a SRMR of 0.022. In this case, the chi-square equals 660.74 with 51 degrees of freedom, the comparative fit index has a value of 0.97 , a root mean square error of approximation is 0.058 , a CI of 90\% [0.054-0.062] and an SRMR of 0.024 . When comparing men and women, the effects of family supportive supervisor behaviors and organizational culture are the same for turnover intention and work-family conflict. This means that the model behaves the same for all the hypotheses. For hypotheses 1 and 2, it found similar results, the chi-squared having a value of 908.47 with 141 degrees of freedom. It includes a $\mathrm{Pr}>\mathrm{Chi}-\mathrm{Sq}<.0001$ for an adjusted goodness of fit index of 0.98 and the comparative fit index here is 0.97 , which represents a root mean square error of approximation of 0.06 . In addition, for hypothesis 3 and hypothesis 4 , we found that FSSB and organizational culture impact work-family conflict the same way that it does in the initial model: chi-square has a value of 1186.19 with 141 degrees of freedom. It includes a $\mathrm{Pr}>\mathrm{Chi}$-Sq $<.0001$ for an adjusted goodness of fit index of 0.98 and the comparative fit index here is 0.96 , representing a root mean square error of approximation of 0.06 . When comparing participants that have children with those without children, the model behaves similarly. Family supportive supervisor behaviors and organizational culture are related negatively to turnover intention and work-family conflict. Hypothesis 1 and hypothesis 2 reveal the impact in turnover intention in the same way that it does in the initial model: chi-square has a value of 708.42 with 141 degrees of freedom. It includes a $\mathrm{Pr}>\mathrm{Chi}-\mathrm{Sq}<.0001$ for an adjusted goodness of fit index of 0.98 and the comparative fit index here is 0.97 , which represents a root mean square error of approximation of 0.05 . Similarly, hypothesis 3 and hypothesis 4 present the effect in work-family conflict and the chi-square has a value of 819.39 for 141 degrees of freedom. It includes a $\mathrm{Pr}>\mathrm{Chi}-\mathrm{Sq}<.0001$ for an adjusted goodness of fit index of 0.99 , and the comparative fit index here is 0.97 , which represents a root mean square error of approximation of 0.05 . We found no statistically significant variations when comparing men and women and those with children and those without children.

\section{Discussion}

These results show a significant negative impact of family supportive supervisor behaviors in the organizational (turnover intention) and individual (work-family conflict) outcomes. At the same time, organizational culture negatively affects turnover intentions and work-family conflict in a public security organization in a Latin America country. As this study suggests, 
supervisor behaviors that support the work-life interface reduce turnover intention and work-family conflict in a public security organization. The present research shows that turnover intention decreases when supervisors support the interface between work and life outside work. This finding is consistent with previous studies for the private sector (Hammer et al., 2009; Idrovo \& Bosch, 2019; Las Heras, Spela, et al., 2015; Odle-Dusseau et al., 2016; Matthews et al., 2014; Mills et al., 2014), for public service organizations such as the armed forces (Dupré \& Day, 2007; Huffman, Adler, Dolan, Castro, et al., 2005), for police (Alhashmi et al., 2017), for healthcare workers (Blanco-Donoso et al., 2021; Deng et al., 2021), and other high-risk occupations (Russell, 2014). When referring to demanding professions, family supportive supervisor behaviors have been found to have a stronger impact in their work and non-work lives due to the special characteristics of these professions. This has been found to be the case for police officers (Amendola et al., 2021; Dick \& Hyde, 2006), military personnel (Dupré \& Day, 2007; Wadsworth \& Southwell, 2011) and national security agencies (Hammer et al., 2019). The present research found the same significant relationship between what supervisors do to help employees integrate their work and life outside work and decisions to stay on the job in a cultural context in which family weighs heavily in the hearts and minds of people. Similarly, the mere existence of strong hierarchies in an organization does not imply that employees have an imminent desire to leave. On the contrary, turnover intention declines when in a hierarchical organization has a culture that permits integrating work and life outside work (Rofcanin et al., 2017; C. A. Thompson et al., 1999). This study coincides with these results, showing that turnover intention decreases even in hierarchical organizations such as a national security organization when norms and attitudes support a balance in work and life outside work. Results also show no significant differences between supervisor behaviors and the organizational culture, which may suggest that in public service organizations, family supportive supervisor behaviors and organizational culture have similar weight in reducing the organization's turnover intention in demanding professions. This finding becomes relevant because of the economic impact of hidden turnover intention. As Holtom et al. (2008) indicated, there is no line in the financial statements that captures the cost of turnovers. This cost in hierarchical organizations and demanding professions is a growing problem, whether in the military (Dupré \& Day, 2007), among police officers or firefighters (Burakova et al., 2014) or nurses (Duxbury \& Halinski, 2018). Moreover, there is an additional challenge: this cost may be higher than for other occupations due to the specific training conditions of these demanding occupations. When focusing on the individual outcome, work-family conflict, both the family supportive supervisor behaviors and organizational culture have a negative impact on work-family conflict. This finding is aligned with what several authors have found for the private sector (Frye \& Breaugh, 2004; J. H. Greenhaus, 2016; Liao et al., 2019). For public service organizations, similar results have been found by Carvalho \& Chambel, (2017), Griffin \& Sun (2018) and Rantanen et al. (2013) for the military and for nurses, social care givers and service sector employees. Similarly, family supportive supervisor behaviors have been associated with reduced work-family conflict among employees in organizations (Hammer et al., 2009; Las Heras, Bosch, et al., 2015) and in the health care sector (Odle-Dusseau et al., 2016). In the latter, their results demonstrated significant beneficial effects of FSSB in organizational commitment, engagement and in job satisfaction. These results support the findings that show a negative relationship between organizational culture and work-family conflict in public security organizations in a Latin America country. Some authors affirmed that when there are some initiatives to embed work-life balance into organizational culture, work-life interface is more favorable and the possibility of conflict is reduced (Brough \& Driscoll, 2010). In public service professions such as firefighters, military officers, paramedics and police officers, Larsson et al., (2016) found that daily troubles were strongly associated with outcomes such as burnout, which is a typical of hierarchical organizations and demanding professions. Holmberg and Alvinius (2019) suggested that bureaucratic and hierarchical structures are characteristics of public service organizations such as the armed forces. The role of organizational culture is crucial to maintain a balance between work and life outside work, given that it represents the instrumental, informational and appraisal support that an employee receives (Rofcanin et al., 2017).

\section{Conclusion}

The main conclusion reached in this research is that the four research hypotheses were confirmed, showing statistically significant relationships, and were therefore accepted. Hypothesis 1: family supportive supervisor behaviors are related negatively to turnover intention in public security organizations. Hypothesis 2 : work-family culture is related negatively to turnover intention in public security organizations. Hypothesis 3: family supportive supervisor behaviors are related negatively to work-family conflict in public security organizations. Hypothesis 4: work-family culture is related negatively to work-family conflict in public security organizations. When comparing men and women, the effects of family supportive supervisor behaviors and work-family culture are the same for turnover intention and work-family conflict. This means that the model behaves the same for all the hypotheses. When comparing participants that have children with those who have no children, no differences were found, so the model behaves similarly. These results imply the importance in public security organizations of the role of supervisors in helping or hindering the work-life balance of their employees. Thus, as expected, supervisors should find different ways to support their employees' work-life balance in order to decrease turnover intention and to diminish conflict between their employees' work and family or personal lives. A second implication is that strategies that have been shown to have a strong significance in this study, such as working effectively to solve employee conflicts between work and non-work issues and taking time to learn about employees' personal needs, may ease the work-life balance among their employees. These recommendations may pose a big challenge to public security agencies and other demanding professions due to the strong hierarchical structure of these organizations. 


\subsection{Recommendation for future research}

Future research should try to collect data from multiple sources within organizations such as the ones mentioned before. It should also focus more on the public sector, and in demanding professions, especially at this time of social unrest and health risks caused by Covid-19, in which police, military personnel, paramedics and health workers are called upon to engage in vital activities for the protection and survival of society.

\section{References}

Alhashmi, M., Jabeen, F., Al-Nasser, A. D., \& Papastathopoulos, A. (2017). The antecedents of employee turnover intentions in the police force in the United Arab Emirates: A conceptual framework. International Journal of Business and Society, $18(\mathrm{~S} 3), 449-462$.

Allen, T. D. (2001). Family-Supportive Work Environments: The Role of Organizational Perceptions. Journal of Vocational Behavior, 58, 414-435. https://doi.org/10.1006/jvbe.2000.1774

Allen, T. D. (2012). The Work and Family Interface. In S. W. J. Kozlowski (Ed.), The Oxford Handbook of Organizational Psychology. https://doi.org/10.1093/oxfordhb/9780199928286.001.0001

Allen, T. D., \& Martin, A. (2017). The work-family interface: A retrospective look at 20 years of research in JOHP. Journal of Occupational Health Psychology, 22(3), 259-272. https://doi.org/10.1037/ocp0000065

Amendola, K. L., Valdovinos Olson, M., Grieco, J., \& Robbins, T. G. (2021). Development of a work-family conflict scale for spouses or partners of police officers. Policing, 44(2), 275-290. https://doi.org/10.1108/PIJPSM-07-2020-0127

Armitage, C. J., \& Conner, M. (2001). Efficacy of the Theory of Planned Behaviour: A Meta-Analytic Review E Y cacy of the Theory of Planned Behaviour: A meta-analytic review. The British Journal of Social Psychology, 40(2001), 471-499. https://doi.org/10.1348/014466601164939

Bayazit, Z. E., \& Bayazit, M. (2017). How do flexible work arrangements alleviate work-family-conflict? The roles of flexibility i-deals and family-supportive cultures. The International Journal of Human Resource Management, 30(3), 405435.

Behson, S. J. (2002). Coping With Family-to-Work Conflict: The Role of Informal Work Accommodations to Family. Journal of Occupational Health Psychology, 7(4), 324-341. https://doi.org/10.1037//1076-8998.7.4.324

Blanco-Donoso, L. M., Moreno-Jiménez, J., Hernández-Hurtado, M., Cifri-Gavela, J. L., Jacobs, S., \& Garrosa, E. (2021). Daily work-family conflict and burnout to explain the leaving intentions and vitality levels of healthcare workers: Interactive effects using an experience-sampling method. International Journal of Environmental Research and Public Health, 18(4), 1-17. https://doi.org/10.3390/ijerph18041932

Bosch, M. J., Heras, M. Las, Russo, M., Rofcanin, Y., \& Grau i Grau, M. (2018). How context matters: The relationship between family supportive supervisor behaviours and motivation to work moderated by gender inequality. Journal of Business Research, 82(September 2017), 46-55. https://doi.org/10.1016/j.jbusres.2017.08.026

Bray, R. M., Camlin, C. S., Fairbank, J. A., Dunteman, G. H., \& Wheeless, S. C. (2010). The Effects of Stress on Job Functioning of Military Men and Women. 27(3), 1-15. https://doi.org/10.1177/0095327X0102700304.The

Brooks, S. K., Greenberg, N., Brooks, S. K., \& Greenberg, N. (2018). Non-deployment factors affecting psychological wellbeing in military personnel : literature review Non-deployment factors affecting psychological wellbeing in military personnel : literature review. Journal of Mental Health, O(0), 1-11. https://doi.org/10.1080/09638237.2016.1276536

Brough, P., \& Driscoll, M. P. O. (2010). Organizational interventions for balancing work and home demands : An overview. Work \& Stress, 24(3), 280-297. https://doi.org/10.1080/02678373.2010.506808

Burakova, M., Ducourneau, J., Gana, K., \& Dany, L. (2014). Pronostic de l'intention de départ chez les sapeurs-pompiers volontaires en France. Psychologie Francaise, 59, 273-299. https://doi.org/10.1016/j.psfr.2013.12.002

Burrell, L. M., Adams, G. A., Durand, D. B., \& Castro, C. A. (2006). The impact of military lifestyle demands on well-being, army, and family outcomes. Armed Forces and Society, 33(1), 43-58. https://doi.org/10.1177/0002764206288804

Byron, K. (2005). A meta-analytic review of work-family conflict and its antecedents. Journal of Vocational Behavior, 67(2), 169-198. https://doi.org/10.1016/j.jvb.2004.08.009

Caillier, J. G. (2016). Does Satisfaction with Family-Friendly Programs Reduce Turnover? A Panel Study Conducted in U.S. Federal Agencies. Public Personnel Management, 45(3), 284-307. https://doi.org/10.1177/0091026016652424

Cameron, K. S., \& Quinn, R. E. (2006). Diagnosing and Changing Organizational Culture: based on the competing values framework. Jossey-Bass.

Campaniço Cavaleiro, S. V., Gomes, C., \& Lopes, M. P. (2019). The Relation Between Family-Supportive Work Environment and Work-Family Conflict: Does Leader Support Act as a Moderator of This Relation in the Portuguese Navy? Armed Forces and Society, 45(2), 291-309. https://doi.org/10.1177/0095327X17746608

Carvalho, V. S., \& Chambel, M. J. (2016). Perceived High-Performance Work Systems and Subjective Balance and WellBeing at Work as Mediators. Journal of Career Developmen, 43(2), 116-129. https://doi.org/10.1177/0894845315583113

Carvalho, V. S., \& Chambel, M. J. (2017). Work-Family Conflict and Enrichment Mediates the Relationship Between Job Characteristics and Well-Being at Work With Portuguese Marine Corps. Armed Forces and Society, 44(2), 301-321. https://doi.org/10.1177/0095327X17698121

Chambel, M. J., Castanheira, F., Oliveira-Cruz, F., \& Lopes, S. (2015). Work context support and Portuguese soldiers' well- 
being: The mediating role of autonomous motivation. Military Psychology, 27(5), 297-310. https://doi.org/10.1037/mil0000087

Chen, S. C., Chiang, Y. H., \& Huang, Y. J. (2017). Exploring the psychological mechanisms linking work-related factors with work-family conflict and work-family facilitation among Taiwanese nurses. International Journal of Human Resource Management, 28(4), 581-602. https://doi.org/10.1080/09585192.2015.1118140

DANE [National Administrative Department of Statistics]. (2018). Demografia y población. https://www.dane.gov.co/index.php/estadisticas-por-tema/demografia-y-poblacion

Demerouti, E., Bakker, A. B., Nachreiner, F., \& Sxhaufeli, W. B. (2001). The Job Demands-Resources Model of Burnout. Journal of Applied Psychology, 86(3), 499-512.

Deng, W., Feng, Z., Yao, X., Yang, T., Jiang, J., Wang, B., Lin, L., Zhong, W., \& Xia, O. (2021). Occupational identity, job satisfaction and their effects on turnover intention among Chinese Paediatricians: a cross-sectional study. BMC Health Services Research, 21(1), 1-12. https://doi.org/10.1186/s12913-020-05991-z

Dick, P., \& Hyde, R. (2006). Line manager involvement in work-life balance and career development: Can't manage, won't manage? British Journal of Guidance and Counselling, 34(3), 345-364. https://doi.org/10.1080/03069880600769480

Dupré, K. E., \& Day, A. L. (2007). The Effects of Supportive Management and Job Quality on Military Personnel. Human Resource Management Review, 46(2), 185-01. https://doi.org/10.1002/hrm

Duxbury, L., \& Halinski, M. (2018). It's not all about guns and gangs: role overload as a source of stress for male and female police officers. Policing and Society, 28(8), 930-946. https://doi.org/10.1080/10439463.2017.1342644

Fantuzzo, J. (2015). A course between bureaucracy and charisma: A pedagogical reading of max weber's social theory. Journal of Philosophy of Education, 49(1), 45-64. https://doi.org/10.1111/1467-9752.12095

Fleetwood, S. (2007). Why work-life balance now? International Journal of Human Resource Management, 18(3), $387-400$. https://doi.org/10.1080/09585190601167441

Flint, D., Haley, L. M., \& McNally, J. J. (2013). Individual and organizational determinants of turnover intent. Personnel Review, 42(5), 552-572. https://doi.org/10.1108/PR-03-2012-0051

French, K. A., Allen, T. D., \& Shockley, K. M. (2018). A Meta-Analysis of Work-Family Conflict and Social Support. Psychological Bulletin, 144(3), 284-314. https://doi.org/10.1037/bul0000120.supp

Frone, M. R., \& Blais, A. R. (2019). Work fatigue in a non-deployed military setting: Assessment, prevalence, predictors, and outcomes. International Journal of Environmental Research and Public Health, 16(16), 1-26. https://doi.org/10.3390/ijerph16162892

Frye, N. K., \& Breaugh, J. A. (2004). Family-Friendly polices, supervisor support, work-family conflict, family - work conflict, and satisfaction: A test of a conceptual. Journal of Business and Psychology, 19(2), 197-221.

Greenhaus, J., Greenhaus, J. H., \& Powell, G. N. (2006). When work and family are allies : A theory of work-family enrichment WHEN WORK AND FAMILY ARE ALLIES : A THEORY OF WORK-FAMILY ENRICHMENT. Academy of Management Review, 31(1), 72-92. https://doi.org/10.5465/AMR.2006.19379625

Greenhaus, J. H. (2016). Work-family relationships. University of Wisconsin-Milwaukee Correspondence.

Greenhaus, J. H., \& Beutell, N. (1985). Sources of Conflict Between Work and Family Roles. Academy of Management Review, 10(1), 76-88. https://doi.org/10.5465/AMR.1985.4277352

Griffin, J. D., \& Sun, I. Y. (2018). Do Work-Family Conflict and Resiliency Mediate Police Stress and Burnout: a Study of State Police Officers. American Journal of Criminal Justice, 43(2), 354-370. https://doi.org/10.1007/s12103-017-9401-y

Haar, J. M., \& Roche, M. A. (2010). Family supportive organization perceptions and employee outcomes : the mediating effects of life satisfaction. 21(7), 999-1014. https://doi.org/10.1080/09585191003783462

Halinski, M., \& Duxbury, L. (2019). Workplace flexibility and its relationship with work-interferes-with-family. Personnel Review, 49(1), 149-166. https://doi.org/10.1108/PR-01-2019-0048

Hammer, L. B., Kossek, E. E., Anger, W. K., Bodner, T., \& Zimmerman, K. L. (2011). Clarifying Work-Family Intervention Processes: The Roles of Work-Family Conflict and Family-Supportive Supervisor Behaviors. Journal of Applied Psychology, 96(1), 134-150. https://doi.org/10.1037/a0020927

Hammer, L. B., Kossek, E. E., Yragui, N. L., Bodner, T. E., \& Hanson, G. C. (2009). Development and Validation of a Multidimensional Measure of Family Supportive Supervisor Behaviors (FSSB). Journal of Management, 35(4), 837-856.

Hammer, L. B., Wan, W. H., Bodner, T., Brockwood, K. J., \& Mohr, C. D. (2019). Supervisor support training effects on veteran health and work outcomes in the civilian workplace. Journal of Applied Psychology, 104(1), 52-69. https://doi.org/10.1037/ap10000354

Han, S. J., \& McLean, G. N. (2020). Effects of family-supportive supervisor behaviors and organizational climate on employees. European Journal of Training and Development, 44(6), 659-674. https://doi.org/10.1108/EJTD-12-20190195

Hatch, N. W., \& Dyer, J. H. (2004). Human capital and learning as a source of sustainable competitive advantage. Strategic Management Journal, 25(12), 1155-1178. https://doi.org/10.1002/smj.421

Hirschi, A., Shockley, K. M., \& Zacher, H. (2019). Achieving Work-Family Balance, an action regulation Model. Academy of Management Review, 44(1), 150-171.

Holmberg, A., \& Alvinius, A. (2019). How pressure for change challenge military organizational characteristics. Defence Studies, 19(2), 130-148. https://doi.org/10.1080/14702436.2019.1575698

Holtom, B. C., Mitchell, T. R., Lee, T. W., \& Eberly, M. B. (2008). Turnover and Retention Research: A Glance at the Past, a Closer Review of the Present, and a Venture into the Future. Academy of Management Annals, 2(1), $231-274$. 
https://doi.org/10.5465/19416520802211552

Huffman, A. H., Adler, A. B., Dolan, C. A., \& Castro, C. A. (2005). The impact of operations tempo on turnover intentions of army personnel. Military Psychology, 17(3), 175-202. https://doi.org/10.1207/s15327876mp1703 4

Huffman, A. H., Adler, A. B., Dolan, C. A., Castro, C. A., Las, M., José, M., Raes, A. M. L., Heras, M. Las, Escribano, P. I., Shockley, K. M., Douek, J., Smith, C. R., Yu, P. P., Dumani, S., French, K. A., Patti, J., Espinosa, A. C., Britt, T. W., Dawson, C. R., ... Jose, M. (2005). The impact of operations tempo on turnover intentions of army personnel. Military Psychology, 17(3), 175-202. https://doi.org/10.1207/s15327876mp1703_4

Hughes, M. G., O’Brien, E. L., Reeder, M. C., \& Purl, J. (2020). Attrition and reenlistment in the Army: Using the Tailored Adaptive Personality Assessment System (TAPAS) to improve retention. Military Psychology, 32(1), 36-50. https://doi.org/10.1080/08995605.2019.1652487

Idrovo Carlier, S., Leon Llorente, C., \& Grau Grau, M. (2012). Comparing work-life balance in Spanish and Latin-American countries. European Journal of Training and Development, 36(2/3), $286-307$. https://doi.org/10.1108/03090591211204751

Idrovo, S., \& Bosch, M. J. (2019). The impact of different forms of organisational support and work-life balance in Chile and Colombia. Academia Revista Latinoamericana de Administracion, 32(3), 326-344. https://doi.org/10.1108/ARLA-102017-0306

Karasek, R. A. (1979). Job Demands, Job De- cision Latitude, and Mental Strain: Innplica- tions for Job Redesign. 24(June). https://doi.org/10.1016/j.matchemphys.2017.03.010

Keaveney, S. M., \& Nelson, J. E. (1993). Coping with organizational role stress: Intrinsic motivational orientation, perceived role benefits, and psychological withdrawal. Journal of the Academy of Marketing Science, 21(113), $113-124$.

Kelly, E. L., Kossek, E. E., Hammer, L. B., Durham, M., Bray, J., Chermack, K., Murphy, L. A., \& Kaskubar, D. (2008). 7 Getting There from Here: Research on the Effects of Work-Family Initiatives on Work-Family Conflict and Business Outcomes. The Academy of Management Annals, 2(1), 305-349. https://doi.org/10.1080/19416520802211610

Kossek, E. E., Petty, R. J., Bodner, T. E., Perrigino, M. B., Hammer, L. B., Yragui, N. L., \& Michel, J. S. (2018). Lasting Impression: Transformational Leadership and Family Supportive Supervision as Resources for Well-Being and Performance. Occupational Health Science, 2(1), 1-24. https://doi.org/10.1007/s41542-018-0012-x

Kossek, E. E., Pichler, S., Bodner, T., \& Hammer, L. B. (2011). Workplace social support and work-family conflict: A metaanalysis clarifying the influence of general and work-family-specific supervisor and organizational support. Personnel Psychology, 64(2), 289-313. https://doi.org/10.1111/j.1744-6570.2011.01211.x

Lachowska, B. H., Szpringer, M., Lachowski, S., \& Porydzaj, K. (2018). Conflict and facilitation between family and occupational roles versus work-related stress in the teachers' group. Medical Studies, 34(1), 41-56. https://doi.org/10.5114/ms.2018.74820

Lapierre, L. M., \& Allen, T. D. (2006). Work-Supportive Family, Family-Supportive Supervision , Use of Organizational Benefits, and Problem-Focused Coping: Implications for Work - Family Conflict and Employee Well-Being. Journal of Occupational Health Psychology, 11(2), 169-181. https://doi.org/10.1037/1076-8998.11.2.169

Lapierre, L. M., Spector, P. E., Allen, T. D., Poelmans, S., Cooper, C. L., O’Driscoll, M. P., Sanchez, J. I., Brough, P., \& Kinnunen, U. (2008). Family-supportive organization perceptions, multiple dimensions of work-family conflict, and employee satisfaction: A test of model across five samples. Journal of Vocational Behavior, 73(1), 92-106. https://doi.org/10.1016/j.jvb.2008.02.001

Larsson, G., Berglund, A. K., \& Ohlsson, A. (2016). Personality and Social Psychology Daily hassles , their antecedents and outcomes among professional first responders : A systematic literature review. Scandinavian Journal of Psychology, 57(1), 359-367. https://doi.org/10.1111/sjop.12303

Las Heras, M., Bosch, M. J., \& Raes, A. M. L. (2015). Sequential mediation among family friendly culture and outcomes. Journal of Business Research, 68(11), 2366-2373. https://doi.org/10.1016/j.jbusres.2015.03.042

Las Heras, M., Spela, H., Pablo, T., \& Escribano, I. (2015). How national context moderates the impact of family-supportive supervisory behavior on job performance and turnover intentions For Authors. Management Research The Journal of the Iberoamerican Academy of Management, 13(6), 55-82. https://doi.org/10.1108/MRJIAM-06-2014-0556

Le, H., Newman, A., Menzies, J., Zheng, C., \& Fermelis, J. (2020). Work-life balance in Asia: A systematic review. Human Resource Management Review, 30(4), 100766. https://doi.org/10.1016/j.hrmr.2020.100766

Lefrancois, M., Saint-charles, J., \& Riel, J. (2017). Work / Family Balancing and 24 / 7 Work Schedules : Network Analysis of Strategies in a Transport Company Cleaning Service. New Solutions: Journal of Environmental and Occupational Health Policy, 27(3), 319-341. https://doi.org/10.1177/1048291117725718

Li, J. C. M., Cheung, J. C. K., \& Sun, I. Y. (2019). The impact of job and family factors on work stress and engagement among Hong Kong police officers. Policing, 42(2), 284-300. https://doi.org/10.1108/PIJPSM-01-2018-0015

Liao, E. Y., Lau, V. P., Hui, R. T. yin, \& Kong, K. H. (2019). A resource-based perspective on work-family conflict: metaanalytical findings. Career Development International, 24(1), 37-73. https://doi.org/10.1108/CDI-12-2017-0236

Lingard, H., Francis, V., Turner, M., \& Lingard, H. (2012). Work time demands , work time control and supervisor support in the Australian construction industry An analysis of work-family interaction. Engineering, Construction and Architectural Management, 19(6), 647-665. https://doi.org/10.1108/09699981211277559

Matthews, R. A., Kath, L. M., \& Barnes-Farrell, J. L. (2010). A short, valid, predictive measure of work-family conflict: item selection and scale validation. Journal of Occupational Health Psychology, 15(1), 75-90. https://doi.org/10.1037/a0017443 
Matthews, R. A., Mills, M. J., Trout, R. C., \& English, L. (2014). Family-supportive supervisor behaviors, work engagement, and subjective well-being: A contextually dependent mediated process. Journal of Occupational Health Psychology, 19(2), 168-181. https://doi.org/10.1037/a0036012

Mccarthy, A., Darcy, C., \& Grady, G. (2010). Author's personal copy Human Resource Management Review Work-life balance policy and practice : Understanding line manager attitudes and behaviors. Human Resource Management Review, 20, 158-167. https://doi.org/10.1016/j.hrmr.2009.12.001

Miller, C. C. (2015). 7 Work Culture's Toll on Families and Gender Equality. The New York Times. https:/www.nytimes.com/2015/05/31/upshot/the-24-7-work-cultures-toll-on-families-and-genderequality.html?_r $=0 \& a b t=0002 \& a b g=0$

Mills, M. J., Matthews, R. A., Henning, J. B., \& Woo, V. A. (2014). Family-supportive organizations and supervisors: How do they influence employee outcomes and for whom? International Journal of Human Resource Management, 25(12), 1763-1785. https://doi.org/10.1080/09585192.2013.860387

Minamizono, S., Nomura, K., Inoue, Y., Hiraike, H., Tsuchiya, A., Okinaga, H., \& Illing, J. (2019). Gender division of labor, burnout, and intention to leave work among young female nurses in japan: A cross-sectional study. International Journal of Environmental Research and Public Health, 16(12), 1-12. https://doi.org/10.3390/ijerph16122201

Mishra, P., \& Bhatnagar, J. (2019). Individual, organizational and social level antecedents of work-family enrichment: Does gender acts as a moderator? Journal of Asia Business Studies, 13(1), 108-132. https://doi.org/10.1108/JABS-10-20170186

Mittal, R., \& Bienstock, J. E. (2019). Transformational leadership and polychronicity as antecedents of work-home boundaries. Management Research Review, 42(4), 460-468. https://doi.org/10.1108/MRR-02-2018-0093

Montgomery, A. J., Panagopolou, E., \& Benos, A. (2006). Work - family interference as a mediator between job demands and job burnout among doctors. Stress and Health, 22(1), 203-212. https://doi.org/10.1002/smi.1104

O’Reilly, C. A., Chatman, J., \& Caldwell, D. F. (1991). People and Organizational Culture: A Profile Comparison Approach to Assessing Person-Organization Fit. In Source: The Academy of Management Journal (Vol. 34, Issue 3, pp. 487-516). https://doi.org/10.2307/256404

O`Neill, O. A., \& Rothbard, N. P. (2015). Is Love All You Need? The Effects of Emotional Culture, Suppression, and Workfamily Conflict on Firefighter Risk-Taking and Health. Academy of Management, 60(1), 78-108. https://doi.org/10.5465/amj.2014.0952

O’Rourke, N., \& Hatcher, L. (2013). A Step-by-Step Approach to Using SAS ${ }^{\circledR}$ for Factor Analysis and Structural Equation Modelling, Second Edition. In International Statistical Review (Vol. 83, Issue 2). https://doi.org/10.1111/insr.12111_2

Odle-Dusseau, H. N., Hammer, L. B., Crain, T. L., \& Bodner, T. E. (2016). The influence of family-supportive supervisor training on employee job performance and attitudes: An organizational work-family intervention. Journal of Occupational Health Psychology, 21(3), 296-308. https://doi.org/10.1037/a0039961

Pecino, V., Diaz-Fúnez, P. A., Mañas-Rodriguez, M. A., Aguilar-Parra, J. M., Padilla-Góngora, D., \& Lopez-Lir, R. (2018). Interpersonal justice climate, extra-role performance and work family balance : A multilevel mediation model of employee well- being. PLOS ONE, 13(11), 1-15.

Pien, L. C., Cheng, W. J., Chou, K. R., \& Lin, L. C. (2021). Effect of work-family conflict, psychological job demand, and job control on the health status of nurses. International Journal of Environmental Research and Public Health, 18(7), 19. https://doi.org/10.3390/ijerph18073540

Powell, G. N., Greenhaus, J. H., Allen, T. D., \& Johnson, R. E. (2019). Introduction to Special Topic Forum Advancing and Expanding Work-Life Theory From Multiple Perspectives. Academy of Management Review, 44(1), 54-71.

Rantanen, J., Kinnunen, U., \& Mauno, S. (2013). Work \& Stress : An International Journal of Work, Health \& Organisations Patterns of conflict and enrichment in work-family balance : A three- dimensional typology. Work \& Stress, 27(2), 141163. https://doi.org/10.1080/02678373.2013.791074

Rasmussen, J. (2020). Share a little of that human touch: The marketable ordinariness of security and emergency agencies' social media efforts. Human Relations. https://doi.org/10.1177/0018726720919506

Rhoades, L., \& Eisenberger, R. (2002). Perceived organizational support: A review of the literature. Journal of Applied Psychology, 87(4), 698-714. https://doi.org/10.1037/0021-9010.87.4.698

Rofcanin, Y., Heras, M. Las, \& Bakker, A. B. (2017). Family Supportive Supervisor Behaviors and Organizational Culture : Effects on Work Engagement and Performance Family Supportive Supervisor Behaviors and Organizational Culture: Effects on Work Engagement and Performance. Journal of Occupational Health Psychology, 22(2), $207-217$. https://doi.org/10.1037/ocp0000036

Russell, L. M. (2014). An empirical investigation of high-risk occupations Leader influence on employee stress and burnout among police. Management Research Review, 37(4), 367-384. https://doi.org/10.1108/MRR-10-2012-0227

Sánchez-Vidal, M. E., Cegarra-Leiva, D., \& Cegarra-Navarrro, J. G. (2012). Gaps between managers ' and employees ' perceptions of work - life balance. The International Journal of Human Resource Management, $23(4), 645-661$. https://doi.org/10.1080/09585192.2011.561219

Schaufeli, W. B., \& Bakker, A. B. (2004). Job demands, job resources, and their relationship with burnout and engagement : a multi-sample study. Journal of Organizational Behavior, 25, 293-315.

Shabir, S., Khan, O. F., \& Gani, A. (2021). Work-life interference: a perpetual struggle for women employees. International Journal of Organizational Analysis, ahead of p(aheadof print). https://doi.org/10.1108/IJOA-04-2020-2133

Sharma, S. (2015). Occupational stress in the armed forces: An Indian army perspective. IIMB Management Review, 27(3), 
185-195. https://doi.org/10.1016/j.iimb.2015.06.002

Shaw, J. D., Gupta, N., \& Delery, J. E. (2005). Alternative conceptualizations of the relationship between voluntary turnover and organizational performance. Academy of Management Journal, 48(1), 50-68. https://doi.org/10.5465/AMJ.2005.15993112

Shockley, K. M., Douek, J., Smith, C. R., Yu, P. P., Dumani, S., \& French, K. A. (2017). Cross-cultural work and family research: A review of the literature. Journal of Vocational Behavior, 101(February), 1-20. https://doi.org/10.1016/j.jvb.2017.04.001

Sonnentag, S., \& Fritz, C. (2015). Recovery from job stress : The stressor-detachment model as an integrative framework. Journal of Organizational Behavior, 103(January 2014), 72-104. https://doi.org/10.1002/job

Thompson, C. A., Beauvais, L. L., \& Lyness, K. S. (1999). When Work-Family Benefits Are Not Enough: The Influence of Work-Family Culture on Benefit Utilization, Organizational Attachment, and Work-Family Conflict. Journal of Vocational Behavior, 54(3), 392-415. https://doi.org/10.1006/jvbe.1998.1681

Thompson, C. A., \& Prottas, D. J. (2005). Relationships Among Organizational Family Support , Job Autonomy , Perceived Control, and Employee Well-Being. 10(4), 100-118. https://doi.org/10.1037/1076-8998.10.4.100

Thompson, C. a, Beauvais, L. L., \& Lyness, K. S. (1999). When work - family benefits are not enough : The influence of work - family culture on benefit utilization , organizational attachment, and work - family conflict. In Journal of Vocational Behavior (Vol. 415, pp. 392-415). https://doi.org/10.1006/jvbe.1998.1681

Thörnqvist, C. (2006). Family-friendly labour market policies and careers in Sweden -and the lack of them.pdf. British Journal of Guidance \& Counselling, 34(3), 309-326.

Väänänen, A., Anttila, E., Turtiainen, J., \& Varje, P. (2012). Formulation of work stress in 1960-2000: Analysis of scientific works from the perspective of historical sociology. Social Science and Medicine, 75(5), 784-794. https://doi.org/10.1016/j.socscimed.2012.04.014

Van der Heijden, B. I. J. M., Peeters, M. C. W., Le Blanc, P. M., \& Van Breukelen, J. W. M. (2018). Job characteristics and experience as predictors of occupational turnover intention and occupational turnover in the European nursing sector. Journal of Vocational Behavior, 108(June), 108-120. https://doi.org/10.1016/j.jvb.2018.06.008

Van Steenbergen, E. F., \& Ellemers, N. (2009). Is managing the work - family interface worthwhile ? Benefits for employee health. Journal of Organizational Behavior, 642(July 2008), 617-642. https://doi.org/10.1002/job

Van Steenbergen, E. F., van der Ven, C., Peeters, M. C. W., \& Taris, T. W. (2018). Transitioning Towards New Ways of Working: Do Job Demands, Job Resources, Burnout, and Engagement Change? Psychological Reports, 121(4), 736-766. https://doi.org/10.1177/0033294117740134

Wadsworth, S. M., \& Southwell, K. (2011). Military Families: Extreme Work and Extreme. $163-183$. https://doi.org/10.1177/0002716211416445

Wu, T. J., Yuan, K. S., Yen, D. C., \& Xu, T. (2019). Building up resources in the relationship between work-family conflict and burnout among firefighters: moderators of guanxi and emotion regulation strategies. European Journal of Work and Organizational Psychology, 28(3), 430-441. https://doi.org/10.1080/1359432X.2019.1596081

Yanos, P. T., DeLuca, J. S., Salyers, M. P., Fischer, M. W., Song, J., \& Caro, J. (2020). Cross-sectional and prospective correlates of associative stigma among mental health service providers. Psychiatric Rehabilitation Journal, 43(2), 85-90. https://doi.org/10.1037/prj0000378

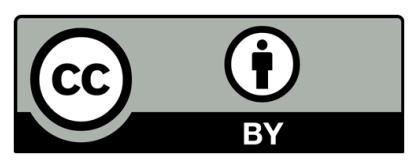

(C) 2021 by the authors; licensee Growing Science, Canada. This is an open access article distributed under the terms and conditions of the Creative Commons Attribution (CC-BY) license (http://creativecommons.org/licenses/by/4.0/). 